\title{
Money-price relation in Malaysia : has it disappeared or strengthened?
}

\begin{abstract}
The paper analyzes empirically the money-price link for the case of Malaysia using quarterly data from 1978 to 2006. Looking at the correlations between cyclical components of monetary aggregates (M1, M2 and M3) and of the price level, we note that the significant correlations documented between money and price during 1978-1987 tend to disappear or become perverse during late 1980s and 1990s. However, for the case of M2 and M3 monetary aggregates, their significant relations with the price level reemerge during 19982006. While time series analyses of cointegration and vector autoregressions (VAR) are uncertain in suggesting the pre-1998 relations between broader monetary aggregates (M2 and M3) and the price level, we note the declining role of M1 monetary aggregate in anticipating future variations in the price level for the recent sample. However, the significant causal influences of M2 and M3 are apparent post-1998. Our results further suggest 4-6-quarter lagged effect of monetary aggregates on the price level. We tend to conclude that the broad monetary aggregates especially M3 is useful for the conduct of monetary policy. (C) 2010 Springer Science+Business Media, LLC.
\end{abstract}

Keyword: Money-price link; Cross correlations; Concordance; VAR; Malaysia. 